\title{
Conductive Properties and Gating of Channels Formed by Syringopeptin 25A, a Bioactive Lipodepsipeptide from Pseudomonas syringae pv. syringae, in Planar Lipid Membranes
}

\author{
Mauro Dalla Serra, ${ }^{1}$ Ivonne Bernhart, ${ }^{1}$ Paola Nordera, ${ }^{1}$ Domenico Di Giorgio, ${ }^{2}$ Alessandro Ballio, ${ }^{2}$ and \\ Gianfranco Menestrina ${ }^{1}$ \\ ${ }^{1}$ CNR-ITC Centro Fisica Stati Aggregati, Via Sommarive 18, I-38050 Povo (Trento), Italy; ${ }^{2}$ Dipartimento di \\ Scienze Biochimiche e Centro CNR di Biologia Molecolare, Roma "La Sapienza," P.le Aldo Moro 5, \\ 00185 Roma, Italy \\ Accepted 22 January 1999.
}

\begin{abstract}
Syringopeptin 25A, a pseudomonad lipodepsipeptide, can form ion channels in planar lipid membranes. Pore conductance is around $40 \mathrm{pS}$ in $0.1 \mathrm{M} \mathrm{NaCl}$. Channel opening is strongly voltage dependent and requires a negative potential on the same side of the membrane where the toxin was added. These pores open and close with a lifetime of several seconds. At negative voltages, an additional pore state of around $10 \mathrm{pS}$ and a lifetime of around $30 \mathrm{~ms}$ is also present. The voltage dependence of the rates of opening and closing of the stable pores is exponential. This allows estimation of the equivalent charge that is moved across the membrane during the process of opening at about 2.6 elementary charges. When $\mathrm{NaCl}$ is present, the pore is roughly 3 times more permeant for anions than for cations. The current voltage characteristic of the pore is nonlinear, i.e., pore conductance is larger at negative than at positive voltages. The maximal conductance of the pore depends on the concentration of the salt present, in a way that varies almost linearly with the conductivity of the solution. From this, an estimate of a minimal pore radius of $0.4 \mathrm{~nm}$ was derived.
\end{abstract}

Additional keyword: selectivity.

Syringopeptins (SPs) are lipodepsipeptides (LDPs) with a cyclic ring that are produced by the gram-negative bacterium Pseudomonas syringae pv. syringae (Ballio et al. 1991), a plant pathogen with a wide host range including plants of economic importance (Bradbury 1986). Although similar to the lipodepsinonapeptides produced by this bacterium, syringomycin (SR), syringotoxin (ST), syringostatins, and pseudomycins (Segre et al. 1989; Ballio et al. 1990, 1994; Fukuchi et al. 1990, 1992; Isogai et al. 1990a, 1990b), SPs are composed of three parts: a long, unbranched, 3-hydroxy fatty acid chain, a hydrophobic peptide chain, and a cyclic ring of seven amino

Corresponding author: Gianfranco Menestrina, CNR-ITC Centro di Fisica degli Stati Aggregati, via Sommarive 18, I-38050 Povo, Trento Italy; Telephone: 39461 314256; Fax: 39461 810628; E-mail: menes@cefsa.itc.it acids at the $\mathrm{C}$ terminus. Two types of SPs have been characterized, syringopeptin $22\left(\mathrm{SP}_{22}\right)$ and syringopeptin $25\left(\mathrm{SP}_{25}\right)$, the difference being that the peptide moiety comprises 22 and 25 amino acid residues, respectively. SPs are basic molecules since the cyclic ring contains two positively charged residues (2,4-diaminobutanoic acid; Ballio et al. 1991; Isogai et al. 1995). In view of their phytotoxic activity (Iacobellis et al. 1992; Di Giorgio et al. 1994, 1996a, 1996b) they appear to be significant virulence factors for $P$. syringae pv. syringae, probably contributing to a variety of plant diseases. They also have antifungal activity, albeit lower than that of the lipodepsinonapeptides (Iacobellis et al. 1992; Di Giorgio et al. 1996b).

In view of their amphipathic nature (see Figure 1) and their analogy to the lipopeptides produced by Pseudomonas tolaasii (Nutkins et al. 1991) and Bacillus spp., e.g., iturins and related branched fatty acid antibiotics (Marion et al. 1986; Peypoux et al. 1986; Maget-Dana and Peypoux 1994; Eshita et al. 1995; Yakimov et al. 1996), it was postulated that the primary site of action of SPs might be the cell membrane (Ballio et al. 1991). In particular, the ability to form transmembrane ion channels appears to be a common motif in the function of all bacterial lipopeptides (Quentin et al. 1982; Bhakdi et al. 1988; MagetDana and Ptak 1990, 1995; Brodey et al. 1991; Sheppard et al. 1991; Hutchison et al. 1995; Feigin et al. 1996).

A very useful model to study the formation of ion channels, which gives an unsurpassed wealth of information on conductance properties, is the planar lipid bilayer (Menestrina 1991; Kagan and Sokolov 1997). Some of the pseudomonad LDPs have been extensively studied with this system, including SRE (Hutchison et al. 1995; Feigin et al. 1996, 1997) and an incompletely purified preparation of ST (Ziegler et al. 1984, 1986). Also, some of the similar lipopeptides from $B a$ cillus spp. have been studied in this way (Maget-Dana et al. 1985a; Maget-Dana and Ptak 1990; Sheppard et al. 1991). In addition, a preliminary demonstration that $\mathrm{SP}_{22}$ forms channels in planar bilayers has been reported, although these pores were not thoroughly characterized (Hutchison and Gross 1997). Here we show that $\mathrm{SP}_{25} \mathrm{~A}$ opens ion channels in planar lipid membranes and we report a complete characterization of their conductance properties. 


\section{RESULTS AND DISCUSSION}

\section{Observation of channels formed by $\mathrm{SP}_{25} \mathrm{~A}$ \\ in planar membranes.}

Addition of nanomolar amounts of $\mathrm{SP}_{25} \mathrm{~A}$ to the $c$ is chamber of a voltage-clamped planar lipid membrane (PLM) consisting of pure phospholipids elicited uniform step increases in the current (Fig. 1), indicating the formation of ionic channels in the bilayer (Hille 1984; Menestrina 1986; Ropele and Menestrina 1989). Pores opened when negative voltages were applied (appearing as discrete downward deflections in the first part of the current trace), but quickly closed again when the voltage was switched to positive values (stepwise decreases in the second part of the trace). This voltagedependent behavior is not uncommon among pore formers of bacterial origin. Typical examples are colicins (Schein et al. 1978; Davidson et al. 1984) and hemolysin A of Escherichia coli (Menestrina et al. 1987; Menestrina and Ropele 1989). It was observed also with SRE (Feigin et al. 1996) and with unpurified ST (Ziegler et al. 1984). It is generally referred to as the "gating" of the pore (Hille 1984) and will be analyzed in detail later. For the moment, we noticed that rather large negative voltages were required to start the opening of the pores in PLMs consisting of a mixture of phosphatidylcholine
(PC), phosphatidylethanolamine (PE), and phosphatidylserine (PS). Interestingly, we observed that in PLMs consisting of asolectin (a natural mixture of phospholipids of plant origin containing approximately $20 \%$ of acidic lipids) much smaller potentials, in the range from -40 to $-60 \mathrm{mV}$, were sufficient to trigger pore opening (not shown). However, asolectin PLMs were not used throughout, because they do not always provide a sufficiently low background conductance. Channel steps had a conductance of about $40 \mathrm{pS}$ at negative voltages and $30 \mathrm{pS}$ at positive voltages. These values are in line with those reported for SRE (Feigin et al. 1996), unpurified ST (Ziegler et al. 1984), and $\mathrm{SP}_{22}$ (Hutchison and Gross 1997), which are all in the range of 20 to $40 \mathrm{pS}$ under similar conditions. They are also similar to those found for tolaasin, another LDP produced by a different Pseudomonas strain, which has a conductance of about $20 \mathrm{pS}$ (Brodey et al. 1991). Different values were observed with branched fatty acid lipopeptides from Bacillus spp., e.g., iturin A (Maget-Dana et al. 1985a, 1985b), mycosubtilin (Maget-Dana and Ptak 1990), bacillomycin (MagetDana et al. 1985a), and surfactin (Sheppard et al. 1991). They all display a larger conductance, which moreover depends on the time elapsed from application and on the peptide dose.

Inspection of single channel traces indicated the existence of additional steplike fluctuations of smaller size (Fig. 1).
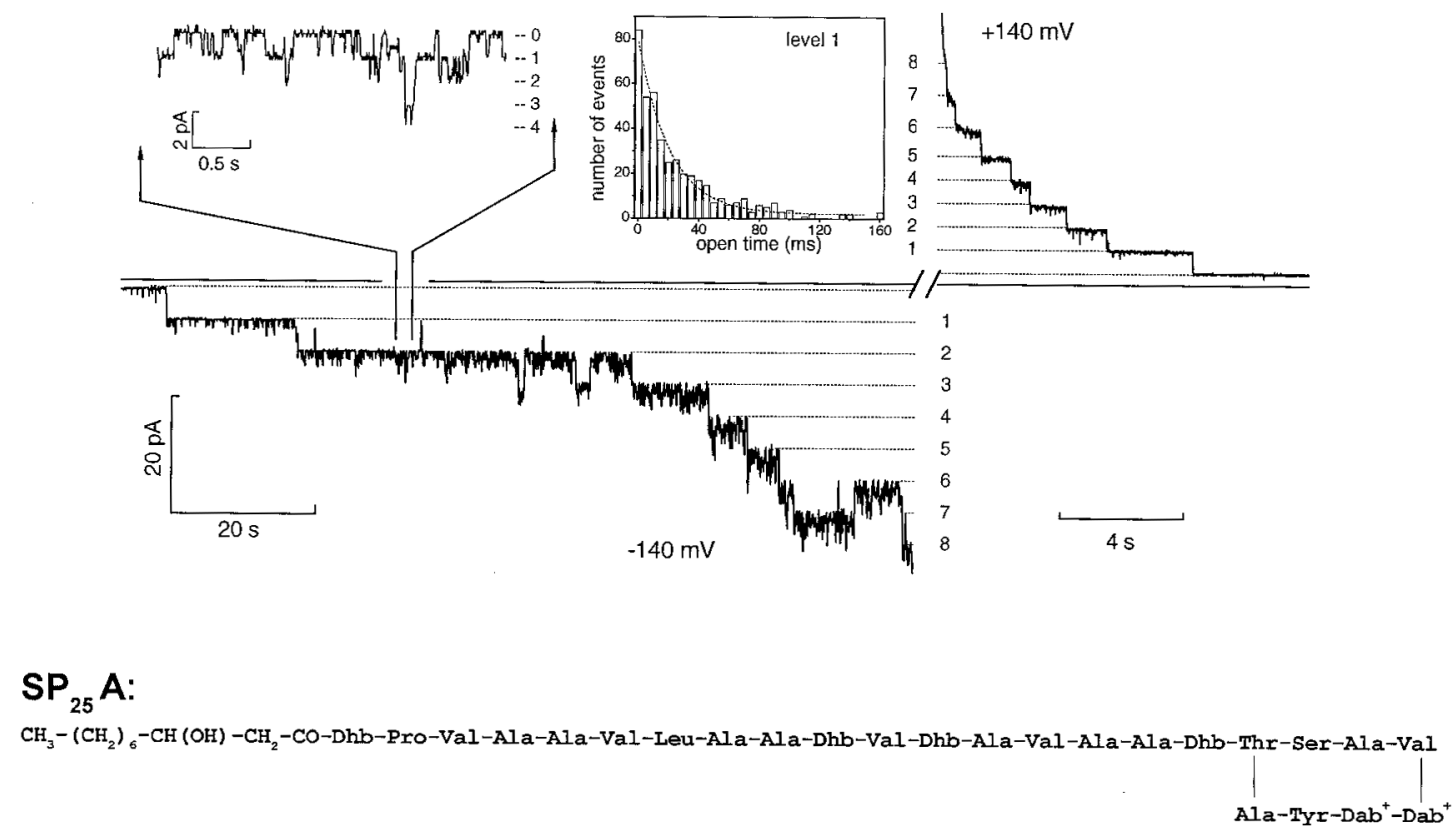

Fig. 1. Formation of ion channels by syringopeptin $25 \mathrm{~A}\left(\mathrm{SP}_{25} \mathrm{~A}\right)$. Discrete fluctuations of the ionic current flowing through the membrane after addition into the aqueous phase of $\mathrm{SP}_{25} \mathrm{~A}$ to a final concentration of $4 \mathrm{nM}$. Buffer was $100 \mathrm{mM} \mathrm{NaCl}, 10 \mathrm{mM}$ MES (morpholinoethanesulfonic acid), $1 \mathrm{mM}$ EDTA, $\mathrm{pH}$ 6.0. The toxin was added to the cis side only (which was maintained at virtual ground). Membrane consisted of a mixture of phosphatidylcholine (PC), phosphatidylethanolamine (PE), and phosphatidylserine (PS) in a 2:2:1 molar ratio. Applied voltage was $\pm 140 \mathrm{mV}$ as indicated. Application of the negative voltage stimulated opening of the channels; switching to the positive voltage produced their closure. Conductance of the pore was 39 $\mathrm{pS}$ at $-140 \mathrm{mV}$ and $29 \mathrm{pS}$ at $+140 \mathrm{mV}$. For a better resolution, a different time scale was used before and after the change in potential (indicated by a break); apart from this the upper trace is exactly the continuation of the lower one. The number of channels open at a given time is indicated next to each dashed lines. We always observed that the number of pores open at the negative voltage matched the number of closings seen after switching to a positive value. The thin solid line indicates zero of current. Smaller channels (approximately $9.5 \mathrm{pS}$ ) were also observed, but only at negative voltages. Their lifetime was very short compared with that of the long-lived channels of $39 \mathrm{pS}$. Nevertheless, they could be clearly resolved, as shown in the amplified selection of trace. In this interval, up to four small channels open at the same time could be detected (indicated next to the trace). Distribution of the lifetime of the small channel (i.e., the dwell time of level 1) is shown in the inset. According to the standard models (Colquohun and Hawkes 1977; Neher and Stevens 1977; Sakmann and Neher 1983) it was curve fitted to a single exponential in order to derive the average lifetime of the open state. Analysis of 427 events provided a mean value of $21 \pm 1 \mathrm{~ms}$. The primary structure of $\mathrm{SP}_{25}$ is reported at the bottom of the figure. Nonstandard amino acids indicated are as follows: Dab, 2,4-diaminobutanoic acid; Dhb, 2,3-dehydro-2-aminobutanoic acid. 
These fluctuations were also strongly voltage dependent, since they appeared only at negative potentials and disappeared at positive voltages much faster than the main pores. Their lifetime (typically tens of milliseconds, as shown in the Figure 1 inset) is also much shorter than that of the larger channels (several seconds). In principle, they could represent either a different kind of pore, formed independently by the same LDP, or an additional feature of the larger channels, in the sense that each of the more conductive pores could also manifest a short-lived ion pathway of additive conductance. Careful analysis of their probability of appearance lead us to favor the second hypothesis (Fig. 2). In fact, we have never observed the stable pores without observing at the same time the fast fluctuations, and in asolectin membranes they appeared at the same, smaller, negative voltages at which the stable pores were observed. Furthermore, during the initial incorporation, the maximum number of small pores that could be simultaneously open increased gradually, in an almost one to one fashion, with the number of large pores present (Fig. 2). The conductance of this state was almost exactly one-fourth that of the stable pore. This suggested a third possibility, i.e., that, in analogy with what was demonstrated with SRE (Kaulin et al. 1998), the large pores are clusters of four small pores opening and closing all together. If this is the case, the formation of a tetrameric cluster should provide a substantial stabilization to the pore, since its lifetime increases by almost three orders of magnitude and no other kind of cluster, larger or smaller, is observed. Cluster size with SRE was six and cluster appearance was concentration dependent (Kaulin et al. 1998). At variance, in our case, we always observed only the large channels at positive voltages, even at the lowest $\mathrm{SP}_{25} \mathrm{~A}$ doses used. Because, on the basis of a time average, the contribution of these small fluctuations to the overall membrane permeability was negligible, we have not analyzed them further.

\section{Voltage dependence of channel gating.}

The rate at which $\mathrm{SP}_{25} \mathrm{~A}$ pores opened during the application of a negative voltage pulse increased strongly with the magnitude of the voltage (Fig. 3). Under such conditions, and if the toxin concentration was large enough, the discrete steps were not evident and the current increase appeared as an almost continuous change (Fig. 3). Applying long-lasting pulses to the membrane, we could observe that the relaxation followed, to a first approximation, a single exponential (see the example in Figure 3B). However, studying the voltage dependence of pore opening by this procedure was very slow and we observed that the experimental conditions (e.g., the number of pores in the membrane) could change significantly before the whole set of $\mathrm{I} / \mathrm{V}$ relaxation was collected (1/f noise). Therefore, we decided to determine only the initial rate of opening of the channels by measuring the slope of the current traces. In fact, in the case of exponential decays the initial rate already contains the information on the time constant (Menestrina and Ropele 1989). This procedure appeared to be sufficiently precise and reproducible for the aim of these experiments, i.e., to evaluate the role of voltage in opening the channels (Fig. 3A). In many cases, an initial delay was present; however, this delay was variable from one trace to the other and, in any case, was only a minor effect compared with the overall relaxation. When large positive voltages were applied, the channels decayed to the closed state following again, to a good approximation, a single exponential relaxation (Fig. 4). The time constant of these decays was also controlled by the applied potential. The voltage dependencies of

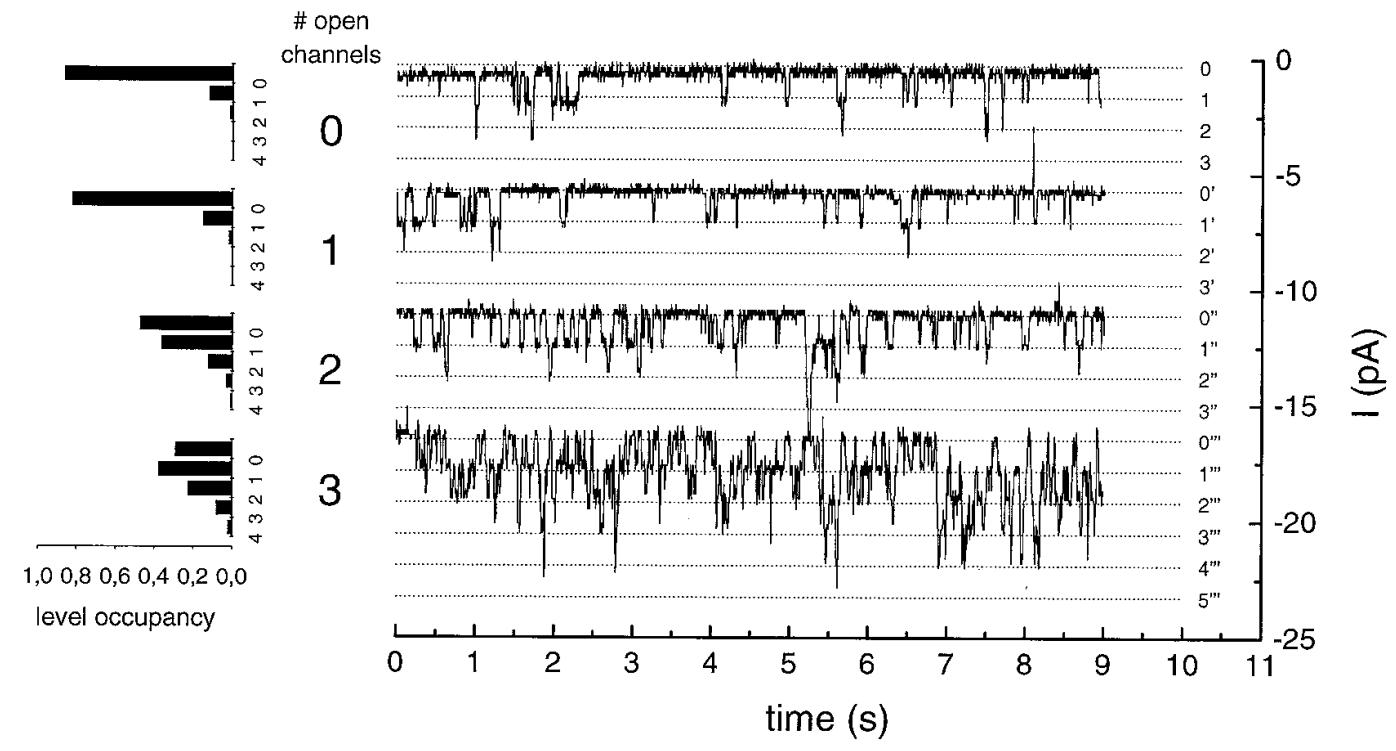

Fig. 2. Characterization of the open probability of the fast fluctuations induced by syringopeptin $25 \mathrm{~A}\left(\mathrm{SP}_{25} \mathrm{~A}\right)$. At negative potentials, fluctuations of smaller size appear on top of the stable channels. The reproduced traces were taken one after the other from a membrane containing an increasing number of stable channels, indicated by the regular shift in the current traces (which are all referred to the same ordinate axis) and marked by the numbers on the left of each trace. Probability of observing $n$ fast-fluctuating channels open at the same time (with $n$ varying between 0 and 4 as exemplified in Figure 1 and reported by the level numbers on the right) is shown by the occupancy histograms reported on the left side of each trace. It appears that, on average, the number of small channels that can be observed to be simultaneously open increases with the number of stable channels present in the membrane. Applied voltage was $-140 \mathrm{mV}$. Other conditions as in Figure 1. Level numbers on the right are primed according to the number of stable channels open at that time. This analysis was extended up to seven large channels open and the results were confirmed (not shown). 
the opening and closing rates are reported together in Figure 5. It appears that both these rates were exponentially regulated by the applied voltage: the rate of opening at the negative potentials increased $e$-fold every $12 \mathrm{mV}$, while that of closing at the positive potentials increased $e$-fold every $45 \mathrm{mV}$ (Fig. 5). A similar behavior was reported for SRE (Feigin et al. 1996). Also in that case negative voltage pulses, opening the channels, were kept short enough to detect only the initial opening phase. In that case, an $e$-fold change was found every $13 \mathrm{mV}$ for the rate of opening and every 24 to $27 \mathrm{mV}$ for the rate of closing. This kind of voltage-dependent gating is a property shared by many pore-forming bacterial toxins besides SRE and ST, e.g., colicins (Schein et al. 1978; Davidson et al. 1984), the RTX hemolysin of E. coli (Menestrina et al. 1987; Menestrina and Ropele 1989), and diphtheria and tetanus toxin (Hoch et al. 1985).
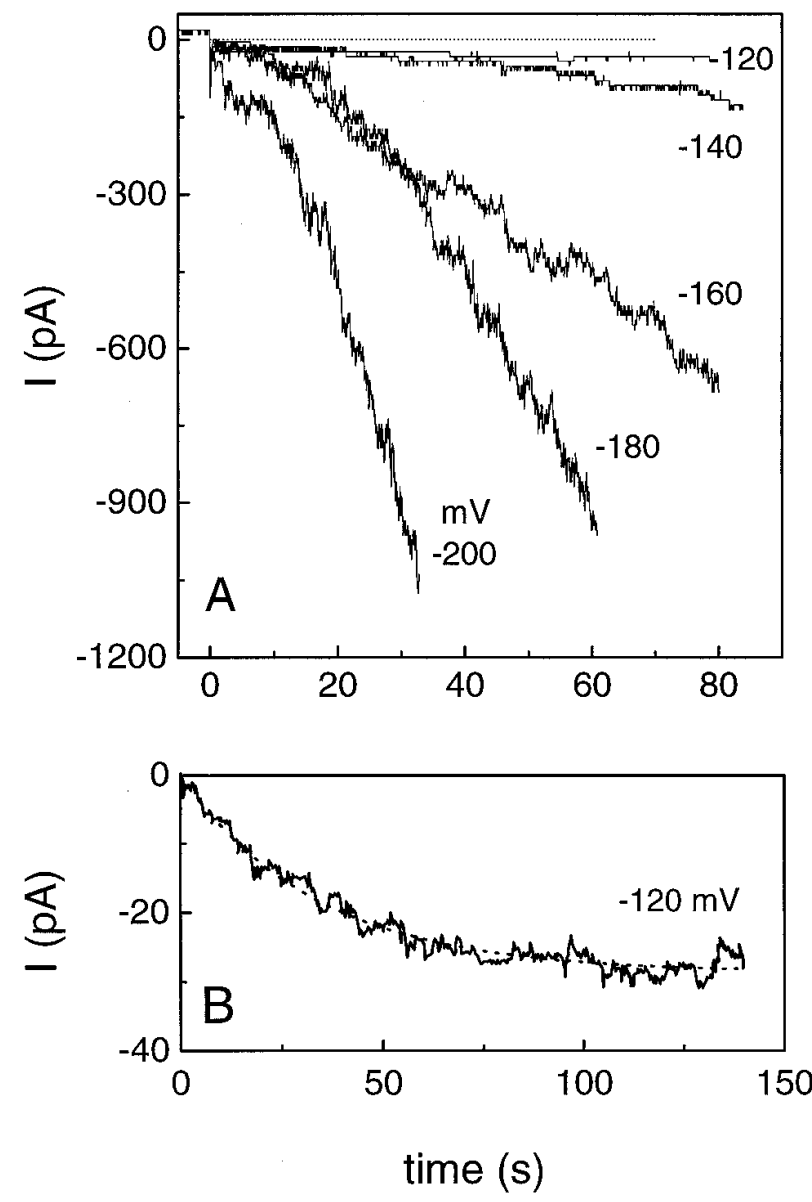

Fig. 3. Voltage dependence of the opening of syringopeptin $25 \mathrm{~A}\left(\mathrm{SP}_{25} \mathrm{~A}\right)$ pores. A, Negative voltage pulses of increasing amplitude were applied to a membrane exposed to $\mathrm{SP}_{25} \mathrm{~A}$ (final concentration $8 \mathrm{nM}$ ). Pores opened at a rate that increased with the applied voltage. When the rate was slow (e.g., -120 and $-140 \mathrm{mV}$ ), it was still possible to distinguish the single channel steps. At higher voltages, the current increase was very large and the discrete steps were no longer apparent. Applied voltage is indicated next to each trace; other conditions are as in Figure 1. Between one trace and the other the channels were closed by application of a long permanence at $+200 \mathrm{mV}$. B, Relaxation of the channels opening after application of a negative voltage pulse of $-120 \mathrm{mV}$ was followed to the steady state. Curve is fitted with a single exponential of time constant $33.3 \mathrm{~s}$. $\mathrm{NaCl}$ concentration was $30 \mathrm{mM}$ and the final $\mathrm{SP}_{25} \mathrm{~A}$ concentration was $4 \mathrm{nM}$; otherwise, experimental conditions are the same as in $\mathbf{A}$.
It is possible to explain the voltage-dependent gating of the pore with a simple two-state model that assumes that the transition between the open and the closed state of the channel corresponds to a major conformational change that occurs after the movement of some charges through the electric field (Ehrenstein and Lecar 1977; Neher and Stevens 1977; Schwarz 1978). The net value of this charge, in elementary units, is given by the following equation (Ehrenstein and Lecar 1977; Schwarz 1978; Menestrina and Ropele 1989): $Q=$ $(m-n) \cdot \mathrm{kT} / e$, where $m$ and $n$ are the slope of the closing and of the opening rate, respectively (from Figure 5), $e$ is the charge of the electron, k the Boltzmann constant, and $T$ the absolute temperature. In our case, we obtained $Q=2.6$ elementary charges. This could be due either to a negative charge going from the cis to the trans side, or to a positive charge moving in the opposite direction. Because $\mathrm{SP}_{25} \mathrm{~A}$ has a net positive charge, provided by the two Dab residues located at the cyclic peptide moiety, the second hypothesis seems to be more likely. Since the toxin was applied at the cis side, these results would imply that the partitioning of the LDP into the membrane, in the pre-open state, leads to a partial embedding of the cyclic peptide moiety into the membrane at least at the level of the glycerol backbone, possibly favored by the inter-

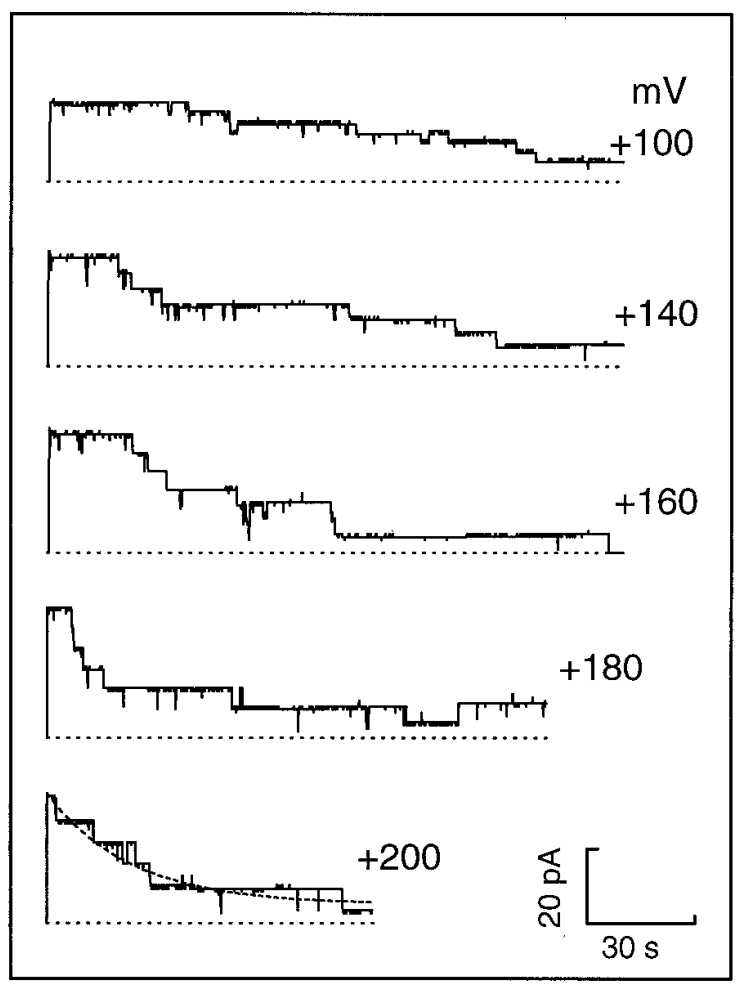

Fig. 4. Voltage dependence of the closing of syringopeptin $25 \mathrm{~A}\left(\mathrm{SP}_{25} \mathrm{~A}\right)$ pores. When large positive voltages were applied the channels switched to the closed state. The decay was well approximated by a single exponential relaxation, as exemplified for the trace at $+200 \mathrm{mV}$. It appears that the time constant of this decay was controlled by the applied potential; in fact closing at $+100 \mathrm{mV}$ was much slower than at $+200 \mathrm{mV}$. Dashed lines indicate zero of current. Because of the positive voltage, the fast fluctuations are completely absent from these traces. Applied voltage is indicated next to each trace; $\mathrm{SP}_{25} \mathrm{~A}$ concentration was $15 \mathrm{nM}$, other conditions as in Figure 1. Between one trace and the other the channels were opened by application of a $-140 \mathrm{mV}$ step. 
action with negatively charged head groups. Such embedded molecules could form small aggregates in the lipid film. Application of a negative voltage might then lead to an open pore by ejecting the positive charges out of the membrane on the cis side, and inducing a major conformational change of the adsorbed LDP. This model is outlined in Figure 5. Assuming that the preformed aggregates are pentamers (see Dalla Serra et al. 1999), the charge we have measured would imply an average displacement of the two charges of the ring from a position at which they sense approximately a quarter of the applied voltage to a position completely outside the field. Interestingly, this would imply that the cycled peptide moiety never crosses the bilayer, thus conserving the original orientation over time even if the channels open and close. This is consistent with our experience, since we have never observed, even after hours, pore opening in the reversed orientation, i.e., with a positive voltage.

\section{Conductive properties of $\mathbf{S P}_{25} \mathrm{~A}$ channels.}

It is possible to determine the selectivity of an ion channel by measuring its current-voltage $(\mathrm{I} / \mathrm{V})$ characteristic in the

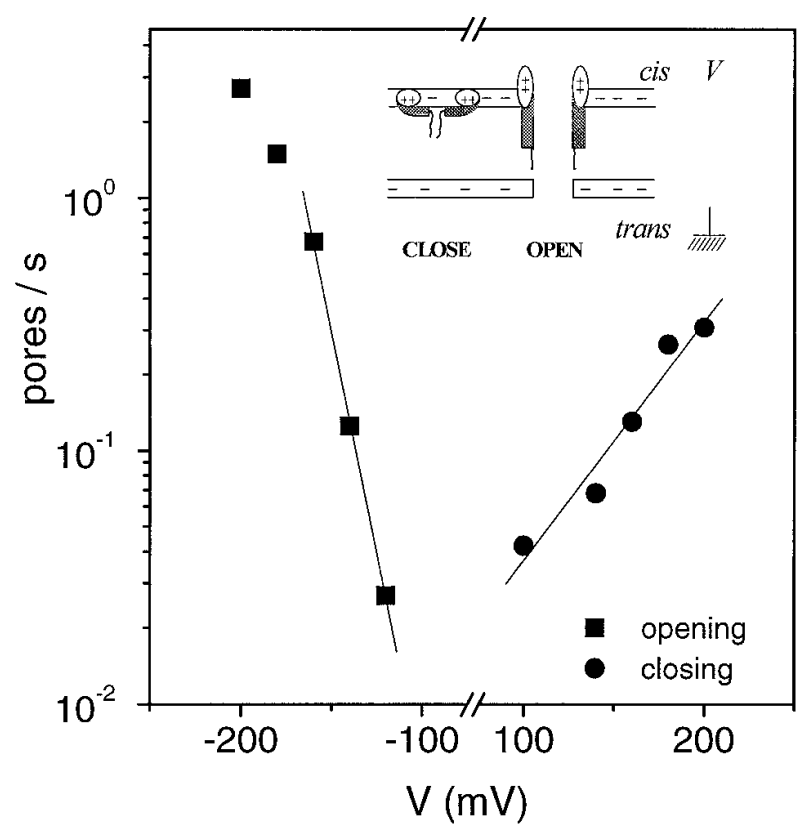

Fig. 5. Voltage dependence of the opening and closing rates. Rate of opening of the channels (calculated from the initial slope of the current traces in Figure 3) and rate of closing (calculated from the time constant of the current relaxation in Figure 4) are reported as a function of the applied voltage in a half logarithmic scale. Both rates show an exponential dependence on voltage, albeit with opposite slope. Rate of opening decreases $e$-fold every $12 \mathrm{mV}$; rate of closing increases $e$-fold every 45 $\mathrm{mV}$. A model of how the voltage dependence may originate is depicted in the upper part. Syringopeptin $25 \mathrm{~A}\left(\mathrm{SP}_{25} \mathrm{~A}\right)$ molecules adsorb onto the membrane with the hydrophobic acyl chain inserted parallel to those of the lipid, whereas the hydrophobic linear peptide chain (shaded part) and the hydrophilic peptide moiety (open ellipse) are still folded together as in solution. The two positively charged Dab residues of the ring are thus partially embedded into the membrane at the level of the glycerol backbone, in favorable interaction with the negatively charged lipid head groups. Adsorbed monomers form small aggregates. Application of a negative voltage at the cis side might favor the opening of a pore by attracting the positive charges out of the membrane and inducing an elongation of the acylated hydrophobic peptide chain to span completely the hydrophobic core of the membrane. presence of a gradient of the salt concentration. In fact, if the cation and the anion in solution have different permeability through the pore, the I/V curve is expected to intersect the voltage axis outside the origin (Schultz 1980; Hille 1984; Menestrina et al. 1987; Cescatti et al. 1991) at a value that is called the reversal voltage $\left(V_{\text {rev }}\right)$. We observed that with $\mathrm{SP}_{25} \mathrm{~A}$ this was indeed the case (Fig. 6). To measure $V_{\text {rev }}$, a triangular wave was used to oscillate the applied voltage between an upper and a lower limit $( \pm 200 \mathrm{mV})$. As expected from the voltage dependence of channel gating, the resulting I/V curve was strongly nonlinear (Fig. 6). Large currents were observed only at negative potentials. A strong hysteresis was also present,

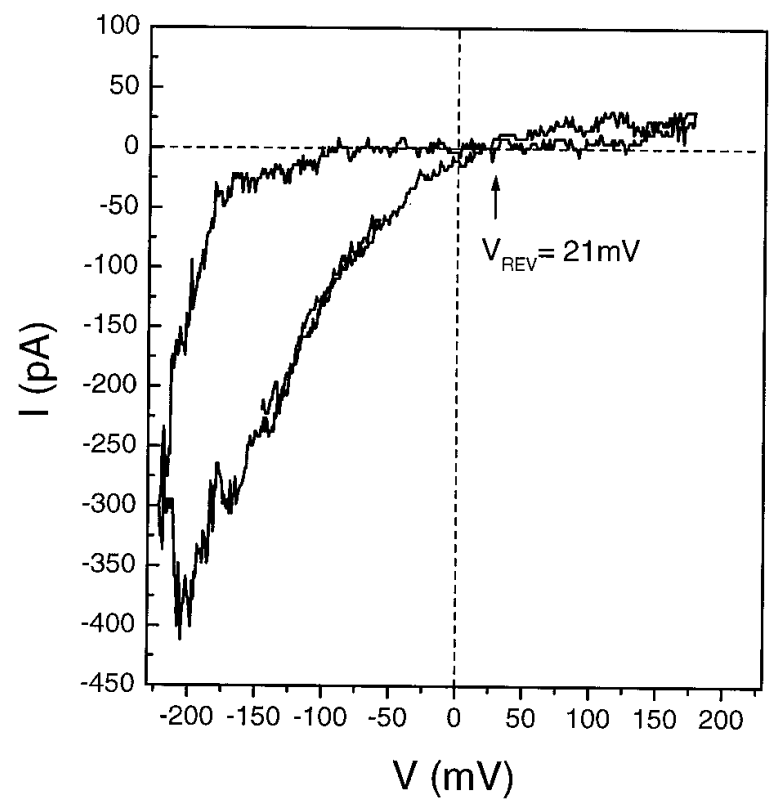

Fig. 6. Determination of cation/anion selectivity of syringopeptin $25 \mathrm{~A}$ $\left(\mathrm{SP}_{25} \mathrm{~A}\right)$ pores. Planar lipid membranes (PLMs) consisting of phosphatidylcholine (PC):phosphatidylethanolamine (PE):phosphatidylserine (PS; in a 2:2:1 molar ratio) were prepared in the presence of a 10-fold transmembrane gradient of $\mathrm{NaCl}$ concentration; the higher concentration, $1 \mathrm{M}$, was in the cis compartment where $5 \mathrm{nM} \mathrm{SP}_{25} \mathrm{~A}$ was also added. The membrane was subjected to a triangular wave of potential $( \pm 200 \mathrm{mV}$ peak to peak, $10-2 \mathrm{~Hz}$ frequency). The reversal potential, i.e., the potential at which no current flows through the membrane, is given by the position at which the two I/V curves intersect (indicated by an arrow). The value of $+21 \mathrm{mV}$ implies a weak anion selectivity $\left(\mathrm{P}_{-} / \mathrm{P}^{+}=3.1\right)$.

Table 1. Anion/cation selectivity of syringopeptin $25 \mathrm{~A}\left(\mathrm{SP}_{25} \mathrm{~A}\right)$ pores

\begin{tabular}{lcccc}
\hline Lipid composition $^{\mathbf{a}}$ & $\begin{array}{c}\mathbf{N a C l}_{\text {cis }} \\
(\mathbf{m M})\end{array}$ & $\begin{array}{c}\mathbf{N a C l}_{\text {trans }} \\
(\mathbf{m M})\end{array}$ & $\begin{array}{c}\boldsymbol{V}_{\text {rev }} \\
(\mathbf{m V})^{\mathbf{b}}\end{array}$ & $\mathbf{P}_{\mathbf{C l} /} / \mathbf{P}_{\mathbf{N a}+}{ }^{\mathbf{c}}$ \\
\hline PC:PE:PS 2:2:1 & 1,000 & 100 & $21 \pm 2$ & 3.0 \\
PC:PE:PS 2:2:1 & 1,000 & 10 & $31 \pm 2$ & 3.6 \\
PC:PE 1:1 & 1,000 & 100 & $20 \pm 2$ & 2.9 \\
\hline
\end{tabular}

${ }^{a}$ Phosphatidylcholine (PC), phosphatidylethanolamine (PE), and phosphatidylserine (PS).

b The reversal voltage, $V_{\text {rev }}$, in the presence of indicated transmembrane gradient of $\mathrm{NaCl}$, was determined as shown in Figure 6. Planar lipid membranes (PLMs) of different composition were used (as indicated). $\mathrm{SP}_{25} \mathrm{~A}$ (5 to $15 \mathrm{nM}$ ) was in the cis compartment. Experiments were done in duplicate.

${ }^{c}$ From $V_{\text {rev }}$ the ratio of the anion over cation permeability $(\mathrm{P}-/ \mathrm{P}+)$ was calculated with the Nernst equation (Schultz 1980; Hille 1984) with appropriate activities for total sodium and chloride amounts present. 
which was mainly due to the fact that while the voltage dependence for opening is very steep, that for closing is much less so (see Figures 3-5). As a consequence, the channels normally close at a quite slower rate than they open. In any case, $V_{\text {rev }}$ is unequivocally determined by the abscissa of the point at which the two I/V curves (ascending and descending) cross each other and the voltage axis. According to the diffusion theory of Nernst, the positive value that we observed indicates anion selectivity (Schultz 1980). As reported in Table 1 , the magnitude of $V_{\text {rev }}$ depends on the gradient applied. These experiments were performed with PLMs consisting of PC:PE:PS (in a 2:2:1 molar ratio). Because the negative surface charge contributed by PS could interfere at least in part with the determination of the electrical properties of the pore (conductance, selectivity, etc.; Ropele and Menestrina 1989) the experiments were also repeated with PC:PE membranes (1:1 molar ratio), which are completely neutral. As shown in Table 1, the results were quite similar, suggesting they were not influenced by the surface potential of the membrane. Applying the Nernst equation (Schultz 1980) we estimated that, independently of membrane composition and gradient magnitude, the channels were anion selective, the permeability ratio $\mathrm{P}\left(\mathrm{Cl}^{-}\right) / \mathrm{P}\left(\mathrm{Na}^{+}\right)$being around 3 (Table 1). It should be emphasized that such selectivity is rather poor when compared for example with the selectivity of endogenous ion channels found in animal or plant cells (Hille 1984). However, this is the kind of situation expected for a toxin pore that is supposed to inflict a rather unselective damage (Menestrina 1991; Kagan and Sokolov 1997) to the target cell. The selectivity properties of these pores correlate nicely with the molecular structure of the component LDP and in particular with the presence at the pore entrance of the uncompensated positive charges of the cyclic peptide moiety (see Figures 5 and 7), which would attract anions and repel cations. Consistently, also ST and SRE pores were found to be anion selective (Ziegler et al. 1986; Feigin et al. 1996), although some authors reported a puzzling cation selectivity for SRE (Hutchison et al. 1995). Among the pores formed by Bacillus spp. lipopeptides those opened by iturin A and mycosubtilin, two uncharged molecules, were slightly anion selective (Maget-Dana et al. 1985b; Maget-Dana and Ptak 1990) whereas those formed by surfactin, which bears two negative charges, were cation selective (Sheppard et al. 1991), confirming the electrostatic attraction model.

The average I/V curve of the single pore, for the case of symmetrical solutions, is reported in Figure 7A. As expected, the intercept is in this case at the origin. Interestingly, one should notice that the I/V curve is markedly nonlinear, implying that the pore conductance (slope of the I/V curve) is larger at negative than at positive potentials. The two conductance values, observed at positive and negative voltages, were called $G_{+}$and $G_{-}$, respectively (as indicated in Figure 7A). The origin of this nonlinearity is conceivably in the asymmetric distribution of the charges on the pore (see the model in Figure 7A). In fact, the presence of positive charges only at the cis pore entrance would accumulate locally the anions and generate a larger anion current when negative voltages, which push the anions through the pore, are applied at the cis side. The contribution of the cation current, albeit minor, would have the same asymmetry. In fact, the positive charges of the pore would repel the cations, reducing in this case their local
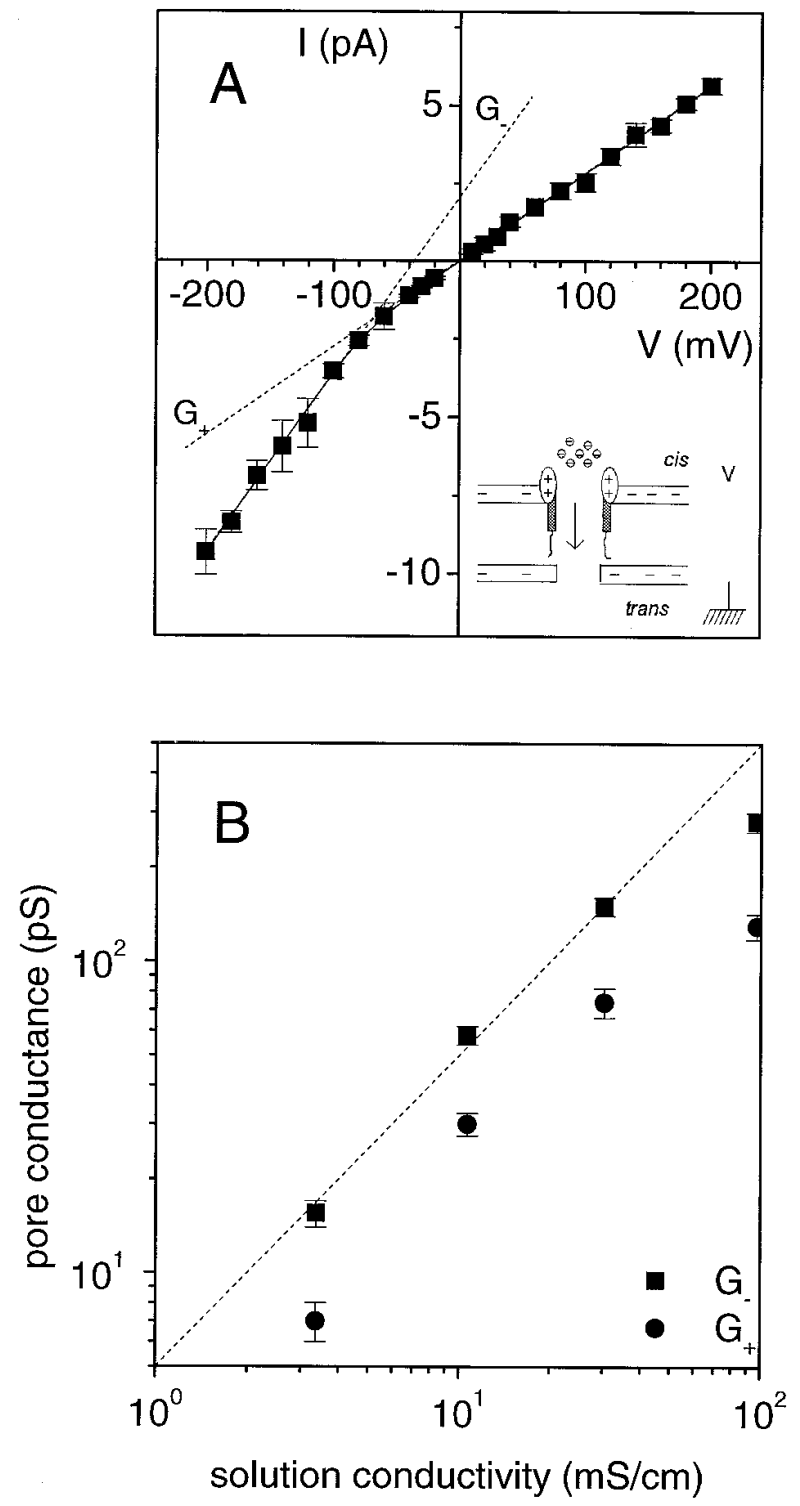

Fig. 7. Dependence of the single channel conductance on the applied potential and the ion concentration. A, The I/V characteristic of the single syringopeptin $25 \mathrm{~A}\left(\mathrm{SP}_{25} \mathrm{~A}\right)$ pore was derived from the amplitude of the current steps observed in a pulsed voltage experiment like that in Figure 1 (for each point at least 20 single steps were averaged). The curve is nonlinear, hence the pore conductance (i.e., the slope of the I/V curve) is larger at negative potentials than at positive. The two limiting slope conductances were called $\mathrm{G}_{+}$and $\mathrm{G}_{-}$, for values observed at positive and negative voltages, respectively. Model of the open pore, introduced in Figure 5, is outlined here again to show how it can also explain this nonlinearity. In fact, the presence of positive charges only at the cis pore entrance would accumulate locally the counterions (anions), thus generating anion selectivity and a larger current when negative voltages are applied at the cis side, and pushing the accumulated anions through the pore (see text for details). B, When $\mathrm{G}_{+}$and $\mathrm{G}_{-}$were reported as a function of solution conductivity, in a double logarithmic plot, an almost linear relationship was obtained, with only a slight tendency to increase sublinearly (more evident in the case of $\mathrm{G}_{-}$). Dashed line has a slope of one and represents a linear dependence. Solution conductivity was changed by varying $\mathrm{NaCl}$ concentration from 0.03 to $1 \mathrm{M} \mathrm{G}_{+}$and $\mathrm{G}_{-}$ were calculated as shown in $\mathbf{A}$ from two to three independent experiments. Other conditions are as in Figure 1. 
concentration at the cis side and resulting in a smaller cation current when positive voltages are applied there. Thus, irrespective of the ion species involved, $G_{-}$is expected to be larger than $\mathrm{G}_{+}$, as we observed.

When $G_{+}$and $G_{-}$were reported as a function of the conductivity of the solution (which was changed by varying the concentration of $\mathrm{NaCl}$ present), an almost linear relationship was obtained (Fig. 7B), with only a slight tendency to increase sub-linearly, a property usually called saturation (Hille 1984). Saturation was more evident in the case of $\mathrm{G}_{+}$. This linear dependence suggests that $\mathrm{SP}_{25} \mathrm{~A}$ forms a water-filled pore. Assuming that the pore is simply a cylindrical hole filled with water, where the mobility of ions is similar to that in the bulk aqueous solution, its conductance $G$ would be related to the solution conductivity $\sigma$ by the following: $\mathrm{G}=\sigma \cdot \pi r^{2} / l$, with $r$ and $l$ the radius and length of the cylinder, respectively. Assuming for the length a value of $5 \mathrm{~nm}$, which applies to the average thickness of a lipid bilayer, a pore radius of $0.28 \mathrm{~nm}$ can be evaluated from $\mathrm{G}_{\text {. }}$. A similar value, $0.25 \mathrm{~nm}$, can be estimated from the conductance of the pores observed previously with unpurified ST (Ziegler et al. 1984). If one takes into consideration the selectivity for $\mathrm{Cl}^{-}$the value of pore radius that we found here for $\mathrm{SP}_{25}$ should be increased to 0.4 $\mathrm{nm}$. In any case, this value remains clearly smaller than that derived from the study of the osmotic protection of erythrocytes (which was $0.9 \mathrm{~nm}$; see Dalla Serra et al. 1999) or that necessary to release calcein from vesicles $(>0.55 \mathrm{~nm})$, an effect that we have also observed (Dalla Serra et al. 1999). The lower value found here probably reflects the fact that application of very simple linear models, like that on which the above equation is based, leads in general to an overestimate of the pore conductance with respect to the experimental value, and the smaller the pore the larger this effect (Smart et al. 1997). In the hypothesis that the large channels are actually clusters of four small channels that are simultaneously open, such as was demonstrated for SR-E (Kaulin et al. 1998), the discrepancy would be even greater. In that case, in fact, the observed cut-off is that of the smaller unit with conductance $10 \mathrm{pS}$. However, it should be noted that, using uncharged polymers, Kaulin et al. (1998) demonstrated that the smaller unit of the SR-E channel (with a conductance of about $4 \mathrm{pS}$ in $0.1 \mathrm{M}$ $\mathrm{NaCl}$ ) has indeed a radius of about $1 \mathrm{~nm}$.

One possible reason for this discrepancy could be that, except for the polar groups at its entrance, all the rest of the $\mathrm{SP}_{25}$ pore is lined by hydrophobic residues or groups (see Figures 1 and 5). This hydrophobic portion, while not preventing water from entering the pore, thus permitting ion flux (as recently shown by the 3D structure of the Streptomyces lividans potassium channel; Doyle et al. 1998), could certainly be a reason for restricting the applicability of the equation $\mathrm{G}=\sigma \cdot \pi r^{2} / l$.

\section{Conclusions.}

We have demonstrated that $P$. syringae $\mathrm{SP}_{25} \mathrm{~A}$ forms stable channels in purely lipidic bilayers. The properties of these channels were fully characterized and found to be in many respects similar to those of other $P$. syringae LDPs. However, some peculiar features were also observed, such as the presence of a fast fluctuating state of very low conductance that had been only recently seen with SRE. Because $\mathrm{SP}_{25} \mathrm{~A}$ appears to be one of the most bioactive $P$. syringae LDPs, at least as a phytotoxin, it should be considered that its effects may be re- lated to its ability to open structurally well-defined ion channels in the membrane of target cells.

\section{MATERIALS AND METHODS}

\section{Chemicals.}

Lipids used were egg PC, egg PE, and brain PS, all purchased from Avanti Polar Lipids (Pelham, AL). Purity was always more than $99 \%$, according to the manufacturer. Different compositions were used as specified in the text. In some experiments we also used asolectin (a mixture of plant phospholipids), repurified from a commercial product (Sigma, St. Louis, MO). Syringopeptin 25A was prepared and purified as previously described (Ballio et al. 1991). Its primary structure is shown in Figure 1.

Planar lipid bilayers were prepared by the apposition technique (Montal and Mueller 1972). Two monolayers were spread from a $6 \mathrm{mg} / \mathrm{ml}$ lipid solution in $\mathrm{n}$-hexane and attached on both sides of a hole $(0.1 \mathrm{~mm}$ in diameter in a $12-\mu \mathrm{m}$ thick Teflon foil) pretreated with n-hexadecane as described previously (Ropele and Menestrina 1989). Normally a mixture consisting of PC:PE:PS in a 2:2:1 molar ratio was used. In some cases (selectivity experiments) the acidic lipid PS was omitted. $\mathrm{SP}_{25} \mathrm{~A}$ was added on one side only (called the cis side) and only to stable, preformed bilayers. Typically, untreated membranes had a capacity of $100 \mathrm{pF}$ and a conductance not exceeding $10 \mathrm{pS}$. Voltage clamp experiments were conducted with a patch clamp amplifier, the Dagan 3900A equipped with the 3910 expander module for PLM application (Dagan Corp., Minneapolis). Membrane current was converted to voltage with a conversion factor of $1 \mathrm{mV} / \mathrm{pA}$, low-pass filtered at 1 $\mathrm{kHz}$ and stored on video cassettes with a PCM recorder (PCM-701ES; Sony, Tokyo) connected to a standard video recorder (JVC HR-D180E). For display and analysis the traces were low-pass filtered at $0.1 \mathrm{kHz}$, acquired on a personal computer and analyzed with the software package pCLAMP 6 (Axon Instruments, Foster City, CA). The trans compartment was the reference and the current was defined positive when cations flowed into that compartment.

$\mathrm{Ag}-\mathrm{AgCl}$ electrodes were used, either directly immersed into the electrolyte solution or connected to it via agarose bridges saturated with $3 \mathrm{M} \mathrm{NaCl}$ (for the selectivity experiments). The bathing solutions ( $4 \mathrm{ml}$ on each side of the hole) contained appropriate concentrations of $\mathrm{NaCl}(100 \mathrm{mM}$ if not otherwise specified), $10 \mathrm{mM}$ MES (morpholinoethanesulfonic acid), and 1 mM EDTA (disodium salt) at pH 6.0 (adjusted by $\mathrm{NaOH}$ ). Experiments were performed at room temperature. In the selectivity experiments the amount of $\mathrm{NaCl}$ added in the two compartments differed (as specified in the text), whereas the other components of the buffer were the same. The junction potential and the possible contribution to it coming from the electrodes were always measured by breaking the membrane at the end of the experiment and recording $V_{\text {rev }}$ under such open-junction conditions. This potential never exceeded a few $\mathrm{mV}$ and it was always subtracted from the $V_{\text {rev }}$ observed with the membrane and the pores.

\section{ACKNOWLEDGMENTS}

This work was financially supported by the Italian Consiglio Nazionale delle Ricerche (CNR), by the Istituto Trentino di Cultura (ITC) and 
by a special grant from the Provincia Autonoma di Trento (PAT, 1913/CONV/1458). M. D. S. was the recipient of a fellowship from CNR (no. 201.02.45-21.02.05). G. F. and P. N. were supported by fellowships from the Comune di Trento - Settore Sviluppo Economico.

\section{LITERATURE CITED}

Ballio, A., Barra, D., Bossa, F., Collina, A., Grgurina, I., Marino, G., Moneti, G., Paci, M., Pucci, P., Segre, A., and Simmaco, M. 1991. Syringopeptins, new phytotoxic lipodepsipeptides of Pseudomonas syringae pv. syringae. FEBS Lett. 291:109-112.

Ballio, A., Bossa, F., Collina, A., Gallo, M., Iacobellis, N. S., Paci, M. Pucci, P., Scaloni, A., Segre, A., and Simmaco, M. 1990. Structure of syringotoxin, a bioactive metabolite of Pseudomonas syringae pv. syringae. FEBS Lett. 269:377-380.

Ballio, A., Bossa, F., Di Giorgio, D., Ferranti, P., Paci, M., Pucci, P., Scaloni, A., Segre, A., and Strobel, G. A. 1994. Novel bioactive lipodepsipeptides from Pseudomonas syringae: The pseudomycins. FEBS Lett. 355:96-100.

Bhakdi, S., Muhly, M., Mannhardt, U., Hugo, F., Klappatek, K., Mueller-Eckhardt, C., and Roka, L. 1988. Staphylococcal alpha-toxin promotes blood coagulation via attack on human platelets. J. Exp. Med. 168:527-542.

Bradbury, J. F. 1986. Guide to Plant Pathogenic Bacteria. CAB Int. Mycol. Inst., Farnham Royal, England.

Brodey, C. L., Rainey, P. B., Tester, M., and Johnstone, K. 1991. Bacterial blotch disease of the cultivated mushroom is caused by an ion channel forming lipodepsipeptide toxin. Mol. Plant-Microbe Interact. 4:407-411.

Cescatti, L., Pederzolli, C., and Menestrina, G. 1991. Modification of lysine residues of $S$. aureus $\alpha$-toxin: Effects on its channel forming properties. J. Membr. Biol. 119:53-64.

Colquohun, D., and Hawkes, A. G. 1977. Relaxation and fluctuations of membrane currents that flow through drug-operated ion channels. Proc. R. Soc. Lond. B 199:231-262.

Dalla Serra, M., Fagiuoli, G., Nordera, P., Bernhart, I., Della Volpe, C., Di Giorgio, D., Ballio, A., and Menestrina, G. 1999. The interaction of lipodepsipeptide toxins from Pseudomonas syringae pv. syringae with biological and model membranes: A comparison of syringotoxin, syringomycin, and two syringopeptins. Mol. Plant-Microbe Interact. 12:391-400.

Davidson, V. L., Brunden, K. R., Cramer, W. A., and Cohen, F. S. 1984. Studies on the mechanism of action of channel-forming colicins using artificial membranes. J. Membr. Biol. 79:105-118.

Di Giorgio, D., Camoni, L., and Ballio, A. 1994. Toxins of Pseudomonas syringae pv. syringae affect $\mathrm{H}^{+}$-transport across the plasma membrane of maize. Physiol. Plant. 91:741-746.

Di Giorgio, D., Camoni, L., Mott, K. A., Takemoto, J. Y., and Ballio, A. 1996a. Syringopeptins, Pseudomonas syringae pv. syringae phytotoxins, resemble syringomycin in closing stomata. Plant Pathol. 45:564-571.

Di Giorgio, D., Lavermicocca, P., Marchiafava, C., Camoni, L., Surico, G., and Ballio, A. 1996b. Effect of syringomycin-E and syringopeptins on isolated plant mitochondria. Physiol. Mol. Plant Pathol. 48: 325-334.

Doyle, D. A., Morais Cabral, J., Pfuetzner, R. A., Kuo, A., Gulbis, J. M., Cohen, S. L., Chait, B. T., and MacKinnon, R. 1998. The structure of the potassium channel: molecular basis of $\mathrm{K}^{+}$conduction and selectivity. Science 280:69-77.

Ehrenstein, G., and Lecar, H. 1977. Electrically gated ionic channels in lipid bilayers. Q. Rev. Biophys. 10:1-34.

Eshita, S. M., Roberto, N. H., Beale, J. M., Mamiya, B. M., and Workman, R. F. 1995. Bacillomycin $\mathrm{L}_{\mathrm{C}}$, a new antibiotic of the iturin group: Isolation, structures and antifungal activities of the congeners. J. Antibiot. 48:1240-1247.

Feigin, A. M., Schagina, L. V., Takemoto, J. Y., Teeter, J. H., and Brand, J. G. 1997. The effect of sterols on the sensitivity of membranes to the channel-forming antifungal antibiotic, syringomycin E. Biochim. Biophys. Acta 1324:102-110.

Feigin, A. M., Takemoto, J. Y., Wangspa, R., Teeter, J. H., and Brand, J. G. 1996. Properties of voltage-gated ion channels formed by syringomycin E in planar lipid bilayers. J. Membr. Biol. 149:41-47.

Fukuchi, N., Isogai, A., Nakayama, J., Takayama, S., and Yamashita, S.
1992. Isolation and structural elucidation of syringostatins, phytotoxins produced by Pseudomonas syringae pv. syringae lilac isolate. J. Chem. Soc. Perkin Trans. 1:875-880.

Fukuchi, N., Isogai, A., Yamashita, S., Suyama, K., Takemoto, J. Y., and Suzuki, A. 1990. Structure of phytotoxin syringomycin produced by a sugar cane isolate of Pseudomonas syringae pv. syringae. Tetrahedron Lett. 31:1589-1592.

Hille, B. 1984. Ionic Channels of Excitable Membranes. Sinauer Assoc. Pub., Sunderland, MA.

Hoch, D. H., Romero-Mira, M., Ehrlich, B. E., Finkelstein, A., DasGupta, B. R., and Simpson, L. L. 1985. Channels formed by botulinum, tetanus, and diphtheria toxins in planar lipid bilayers: Relevance to translocation of proteins across membranes. Proc. Natl. Acad. Sci. USA 82:1692-1696.

Hutchison, M. L., and Gross, D. C. 1997. Lipopeptide phytotoxins produced by Pseudomonas syringae pv. syringae: Comparison of the biosurfactant and ion channel-forming activities of syringopeptin and syringomycin. Mol. Plant-Microbe Interact. 10:347-354.

Hutchison, M. L., Tester, M. A., and Gross, D. C. 1995. Role of biosurfactant and ion channel-forming activities of syringomycin in transmembrane ion flux: A model for the mechanism of action in the plantpathogen interaction. Mol. Plant-Microbe Interact. 8:610-620.

Iacobellis, N. S., Lavermicocca, P., Grgurina, I., Simmaco, M., and Ballio, A. 1992. Phytotoxic properties of Pseudomonas syringae pv. syringae toxins. Physiol. Mol. Plant Pathol. 40:107-116.

Isogai, A., Fukuchi, N., Yamashita, S., Suyama, K., and Suzuki, A. 1990a. Syringostatins, novel phytotoxins produced by Pseudomonas syringae pv. syringae. Agric. Biol. Chem. 53:3117-3119.

Isogai, A., Fukuchi, N., Yamashita, S., Suyama, K., and Suzuki, A. 1990b. Structures of syringostatins A and B, novel phytotoxins produced by Pseudomonas syringae pv. syringae isolated from lilac blights. Tetrahedron Lett. 31:695-698.

Isogai, A., Iguchi, H., Nakayama, J., Kusai, A., Takemoto, J. Y., and Suzuki, A. 1995. Structural analysis of new syringopeptins by tandem mass spectrometry. Biosci. Biotechnol. Biochem. 59:1374-1376.

Kagan, B. L., and Sokolov, Y. 1997. Use of lipid bilayer membranes to detect pore formation by toxins. Pages 395-409 in: Bacterial Pathogenesis. V. L. Clark and P. M. Bavoil, eds. Academic Press, San Diego, CA.

Kaulin, Y. A., Schagina, L. V., Bezrukov, S. M., Malev, V. V., Feigin, A M., Takemoto, J. Y., Teeter, J. H., and Brand, J. G. 1998. Cluster organization of ion channels formed by the antibiotic syringomycin $\mathrm{E}$ in bilayer lipid membranes. Biophys. J. 74:2918-2925.

Maget-Dana, R., Heitz, F., Ptak, M., Peypoux, F., and Guinand, M. 1985a. Bacterial lipopeptides induce ion-conducting pores in planar bilayers. Biochem. Biophys. Res. Commun. 129:965-971.

Maget-Dana, R., and Peypoux, F. 1994. Iturins, a special class of poreforming lipopeptides: Biological and physicochemical properties. Toxicology 87:151-174.

Maget-Dana, R., and Ptak, M. 1990. Iturin lipopeptides: Interaction of mycosubtilin with lipids in planar membranes and mixed monolayers. Biochim. Biophys. Acta 1023:34-40.

Maget-Dana, R., and Ptak, M. 1995. Interactions of surfactins with membrane models. Biophys. J. 68:1937-1943.

Maget-Dana, R., Ptak, M., Peypoux, F., and Michel, G. 1985b. Poreforming properties of iturin A, a lipopeptide antibiotic. Biochim. Biophys. Acta 815:405-409.

Marion, D., Genest, M., Caille, A., Peypoux, F., Michel, G., and Ptak, M. 1986. Conformational study of bacterial lipopeptides. Refinement of the structure of iturin A in solution by two-dimensional ${ }^{1} \mathrm{H}-\mathrm{NMR}$ and energy calculations. Biopolymers 25:153-165.

Menestrina, G. 1986. Ionic channels formed by Staphylococcus aureus alpha-toxin: Voltage dependent inhibition by di- and trivalent cations. J. Membr. Biol. 90:177-190.

Menestrina, G. 1991. Electrophysiological methods for the study of toxin-membrane interaction. Pages 215-241 in: Sourcebook of Bacterial Protein Toxins. J. E. Alouf and J. H. Freer, eds. Academic Press, London.

Menestrina, G., Mackman, N., Holland, I. B., and Bhakdi, S. 1987. Escherichia coli haemolysin forms voltage-dependent channels in lipid membranes. Biochim. Biophys. Acta 905:109-117.

Menestrina, G., and Ropele, M. 1989. Voltage-dependent gating properties of the channel formed by E. coli hemolysin in planar lipid membranes. Biosci. Rep. 9:465-473. 
Montal, M., and Mueller, P. 1972. Formation of bimolecular membranes from lipid monolayers and a study of their electrical properties. Proc. Natl. Acad. Sci. USA 69:3561-3566.

Neher, E., and Stevens, C. F. 1977. Conductance fluctuations and ionic pores in membranes. Annu. Rev. Biophys. Bioeng. 6:345-381.

Nutkins, J. C., Mortishire-Smith, R. J., Packman, L. C., Brodey, C. L., Rainey, P. B., Johnstone, K., and Williams, D. H. 1991. Structure determination of tolaasin, an extracellular lipodepsipeptide produced by the mushroom pathogen Pseudomonas tolaasi Paine. J. Am. Chem. Soc. 113:2621-2627.

Peypoux, F., Pommier, M. T., Marion, D., Ptak, M., Das, C., and Michel, G. 1986. Revised structure of mycosubtilin, a peptidolipid antibiotic from Bacillus subtilis. J. Antibiot. 39:636-641.

Quentin, M. J., Besson, F., Peypoux, F., and Michel, G. 1982. Action of peptidolipidic antibiotics of the iturin group on erythrocytes. Effect of some lipids on haemolysis. Biochim. Biophys. Acta 684: 207-211.

Ropele, M., and Menestrina, G. 1989. Electrical properties and molecular architecture of the channel formed by E. coli hemolysin in planar lipid membranes. Biochim. Biophys. Acta 985:9-18.

Sakmann, B., and Neher, E. 1983. Single Channel Recording. Plenum Press, New York.

Schein, S. J., Kagan, B. L., and Finkelstein, A. 1978. Colicin K acts by forming voltage-dependent channels in phospholipid bilayer membranes. Nature 276:159-163.
Schultz, S. G. 1980. Basic Principles of Membrane Transport. Cambridge University Press, New York.

Schwarz, G. 1978. On the physico-chemical basis of voltage-dependent molecular gating mechanisms in biological membranes. J. Membr. Biol. 43:127-148.

Segre, A., Bachmann, R. C., Ballio, A., Bossa, F., Grgurina, I., Iacobellis, N. S., Marino, G., Pucci, P., Simmaco, M., and Takemoto, J. Y. 1989. The structure of syringomycins A1, E and G. FEBS Lett. 255:27-31.

Sheppard, J. D., Jumarie, C., Cooper, D. G., and Laprade, R. 1991. Ionic channels induced by surfactin in planar lipid bilayer membranes. Biochim. Biophys. Acta 1064:13-23.

Smart, O. S., Breed, J., Smith, G. R., and Sansom, M. S. P. 1997. A novel method for structure-based predictions of ion channel conductance properties. Biophys. J. 72:1109-1126.

Yakimov, M. M., Fredrickson, H. L., and Timmis, K. N. 1996. Effect of heterogeneity of hydrophobic moieties on surface activity of lychenysin A, a lipopeptide biosurfactant form Bacillus licheniformis BAS50. Biotechnol. Appl. Biochem. 23:13-18.

Ziegler, W., Pavlovkin, J., and Pokornj, J. 1984. Effect of syringotoxin on the permeability of bilayer lipid membranes. Biologia (Bratislava) 39:693-699.

Ziegler, W., Pavlovkin, J., Remis, D., and Pokornj, J. 1986. The anion/cation selectivity of the syringotoxin channel. Biologia (Bratislava) 41:1091-1096. 